\title{
Interaction of Actin Filaments with the Plasma Membrane in Amoeba proteus: Studies Using a Cell Model and Isolated Plasma Membrane
}

\author{
Tomomi Kawakatsu, Asako Kikuchi, Teruo Shimmen, and Seiji Sonobe \\ Department of Life Science, Faculty of Science, Himeji Institute of Technology, Harima Science Park City, \\ Hyogo 678-1297, Japan
}

\begin{abstract}
We prepared a cell model of Amoeba proteus by mechanical bursting to study the interaction between actin filaments (AFs) and plasma membrane (PM). The cell model prepared in the absence of $\mathrm{Ca}^{2+}$ showed remarkable contraction upon addition of ATP. When the model was prepared in the presence of $\mathrm{Ca}^{2+}$, the cytoplasmic granules formed an aggregate in the central region, having moved away from PM. Although this model showed contraction upon addition of ATP in the presence of $\mathrm{Ca}^{2+}$, less contraction was noted. Staining with rhodamine-phalloidin revealed association of AFs with PM in the former model, and a lesser amount of association in the latter model. The interaction between AFs and PM was also studied using the isolated PM. AFs were associated with $\mathrm{PM}$ isolated in the absence of $\mathrm{Ca}^{2+}$, but were not when $\mathrm{Ca}^{2+}$ was present. These results suggest that the interaction between $\mathrm{AFs}$ and PM is regulated by $\mathrm{Ca}^{2+}$.
\end{abstract}

Key words: actin filaments/Amoeba proteus/amoeboid movement/calcium ion/plasma membrane/pseudopod formation

The free living giant amoeba, Amoeba proteus, locomotes by extending pseudopods into which endoplasm flows, an action called amoeboid movement (Grebecki, 1994). Although the endoplasmic flow is thought to be induced by an intracellular difference of hydrostatic pressure generated by localized contraction of the actomyosin system (D'haese and Hinssen, 1974; Kuroda and Sonobe, 1981; Lee and Taylor, 1993; Taylor et al., 1980; Yanai et al., 1996), many questions remain as to the mechanism of amoeboid movement.

One question concerns the process of pseudopod formation. Actin polymerization pushing out plasma membrane (PM) is thought to be responsible for pseudopod extension in animal cells and Dictyostelium amoeba (Condeelis, 1977; Miyata et al., 1999; Theriot and Mitchison, 1991; Yumura and Fukui, 1998). However, this does not seem to be the case in giant amoeba which does not have actin filaments (AFs) in their pseudopod (Grebecki, 1990).

Department of Life Science, Faculty of Science, Himeji Institute of Technology, Harima Science Park City, Hyogo 678-1239, Japan.

Tel: +81-791-58-0176, Fax: +81-791-58-0175

E-mail: sonobe@sci.himeji-tech.ac.jp

Abbreviations: AFs, actin filaments; DTT, dithiothreitol; EGTA, ethylene glycol bis(2-aminoethylether)-N, N, N', N'-tetraacetic acid; PIPES, piperazine-N, N'-bis(2-ethanesulfonic acid); PM, plasma membrane; PMSF, phenylmethylsulfonyl fluoride; RP, rhodamine-phalloidin.
Biochemical and ultrastructural evidences have shown that the actomyosin system is responsible for amoeboid movement (Condeelis, 1977; Kuroda and Sonobe, 1981; Sonobe and Kuroda, 1986). Stockem et al. (Stockem et al., 1982) found the presence of bundles of AFs beneath PM and their dissociation from PM at a site of pseudopod formation. These observations suggested that a portion of PM, where AFs detached, was pushed out by internal pressure, inducing the extension of a pseudopod. However, little is known about the molecular mechanism of interaction between AFs and PM in giant amoeba.

The involvement of free $\mathrm{Ca}^{2+}$ in the regulation of amoeboid movement has been reported (Kuroda and Sonobe, 1981; Lee et al., 1993; Taylor et al., 1973). In giant amoeba, free $\mathrm{Ca}^{2+}$ is involved in the regulation of actomyosin-related phenomena, such as motive force generation, gel-sol transformation and pinocytosis (Kuroda and Sonobe, 1981; Lee et al., 1993; Taylor et al., 1973, 1980). Taylor et al. (1980) reported an increased concentration of free $\mathrm{Ca}^{2+}$ in both the tail and tip region of pseudopods. This result suggested that free $\mathrm{Ca}^{2+}$ was involved in the mechanism of the pseudopod formation. Thus, the possible involvement of free $\mathrm{Ca}^{2+}$ should be examined in the regulation of the interaction between AFs and PM. However, the uniform distribution of free $\mathrm{Ca}^{2+}$ throughout the cytoplasm has been also reported by Cobbold (Cobbold, 1980). A reevaluation of the dynam- 
ics of free $\mathrm{Ca}^{2+}$ in giant amoeba is thus needed.

Cell model systems have played important roles in studies on the mechanisms of various types of cell motility (Allen, 1961; Kuroda and Sonobe, 1981; Lee et al., 1991; Taylor et al., 1973, 1976). Demembranated models and glycerinated models have been used in studies on amoeboid movement (Kuroda and Sonobe, 1981; Taylor et al., 1973). However, these model systems are less suitable for studies on the interaction between AFs and PM, because PM is damaged in such models. In this work, we developed a cell model that is permeabilized by mechanical bursting. Using this model and the isolated PM, we tried to elucidate the interaction between AFs and PM, and the function of $\mathrm{Ca}^{2+}$ in it.

\section{Materials and Methods}

\section{Cell culture}

Amoeba proteus was cultured in a Prescott and James solution (PJ solution) (Prescott and James, 1955) in a plastic box $(30 \times 22 \times 5 \mathrm{~cm})$ at $25^{\circ} \mathrm{C}$ and fed Tetrahymena pyriformis. The amoeba was kept under starvation condition for at least two days to reduce the number of food vacuoles before use.

\section{Preparation of cell model}

PJ solution containing amoebae was dropped onto a slide glass. After the amoebae had settled on the glass surface, the PJ solution was replaced with test solutions (Table I). Next, a cover slip was set over the slide, and the test solution was gradually removed using a piece of filter paper. Amoebae were compressed between the slide glass and the cover slip until they finally burst. Two opposite edges of the cover slip were fixed to the slide glass with nail manicure. Test solutions supplemented with $2 \mathrm{mM}$ ATP (Table I) were applied to the cell models by perfusion. The concentration of free $\mathrm{Ca}^{2+}$ in the test solutions was calculated according to Cande (Cande, 1980). The solution lacking $\mathrm{CaCl}_{2}$ was called the test solution (EGTA). Experiments were carried out under an inverted microscope (SHZ-OLLD, Olympus, Japan). To examine the involvement of actin in the motility of models, $10 \mu \mathrm{g} / \mathrm{ml}$ cytochalasin B (Sigma, St. Louis, MO, USA; $20 \mathrm{mg} / \mathrm{ml}$ stock in dimethylsulfoxide) was added to the test solutions.

\section{Isolation of plasma membrane}

About $1 \mathrm{~g}$ of amoeba was collected by centrifugation at 2,000 rpm for 1 min (Himac SCT5B, Hitachi Co., Ltd., Japan) at room temperature, and washed twice with distilled water. Cells resuspended in an extraction medium (10 mM EGTA, $1 \mathrm{mM} \mathrm{MgCl}_{2}, 2 \mathrm{mM}$ DTT, 1 mM PMSF, 50 mM PIPES buffer, pH 7.0; EMP medium) were homogenized using a syringe equipped with a $22 \mathrm{G}$ needle. To examine the effect of $\mathrm{Ca}^{2+}$ in the extraction medium on the characteristics of the isolated membrane, EGTA of the EMP medium was substituted by $1 \mathrm{mM} \mathrm{CaCl}_{2}$. The homogenate was mixed with 50\% Percoll (Amersham-Pharmacia Biotech., Inc., Uppsala,
Table I. COMPOSITION OF TEST SOLUTION

\begin{tabular}{|c|c|c|c|c|}
\hline & \multicolumn{4}{|c|}{ Test solutions } \\
\hline & EGATA & $10^{-8} \mathrm{M} \mathrm{Ca}^{2+}$ & $10^{-6} \mathrm{M} \mathrm{Ca}^{2+}$ & $10^{-4} \mathrm{M} \mathrm{Ca}^{2+}$ \\
\hline EGTA & 5 & 5 & 5 & 5 \\
\hline PIPES & 25 & 25 & 25 & 25 \\
\hline $\mathrm{KCl}$ & 30 & 30 & 30 & 30 \\
\hline $\mathrm{MgCl}_{2}$ & 2 & 2 & 2 & 2 \\
\hline $\mathrm{CACL}_{2}$ & - & 0.23 & 4.14 & 5.9 \\
\hline
\end{tabular}

Concentration of chemical is shown in $\mathrm{mM}$. The $\mathrm{pH}$ value was adjusted with $\mathrm{KOH}$.

Sweden) in $0.5 \mathrm{M}$ mannitol and centrifuged at $12,500 \times \mathrm{g}$, at $25^{\circ} \mathrm{C}$ for $60 \mathrm{~min}$. Fragments of PM were collected from the uppermost layer in the centrifuge tube and washed with EMP medium. Hereafter, $\mathrm{PM}$ isolated in the absence or presence of $\mathrm{Ca}^{2+}$ is called PM $\left(-\mathrm{Ca}^{2+}\right)$ or $\mathrm{PM}\left(+\mathrm{Ca}^{2+}\right)$, respectively.

\section{Observation of actin}

Cell models sandwiched between a slide glass and a cover slip were fixed with a fixation solution $(3.7 \%$ formaldehyde, $0.5 \mathrm{mM}$ EGTA, $2 \mathrm{mM} \mathrm{MgCl}_{2}, 50 \mathrm{mM}$ PIPES, $\mathrm{pH}$ 7.0) by perfusion for 1 hour. After washing with EMP medium, samples were incubated with $0.03 \mu \mathrm{M}$ rhodamine-phalloidin (RP) (Molecular Probes, Inc., Eugene, OR) in EMP medium.

AFs associated with the isolated PM were stained with $0.03 \mu \mathrm{M}$ RP without fixation. To identify PM, 1/50 volume of FITC-conjugated Concanavalin A (Vector Laboratories, Inc., Burlingame, CA) was added to the fraction. Samples were examined by epifluorescence microscope (BH2-RFCA, Olympus, Japan) and recorded on T-MAX400 film (Kodak, Rochester, NY, USA).

\section{Preparation of myosin subfragment-1}

Subfragment-1 of rabbit skeletal muscle myosin was prepared according to Margossian and Lowey (Margossian and Lowey, 1982).

\section{Results}

\section{Cell model}

To prepare the cell models, amoeba in test solutions containing various concentrations of $\mathrm{Ca}^{2+}$ without ATP were sandwiched between a slide glass and a cover slip and compressed by removing the solution with a piece of filter paper until they burst. When the cells burst, some of the cytoplasmic granules flowed out. No movement was observed in the model unless ATP was added. In the cell model prepared in test solution of $10^{-6} \mathrm{M}$ or $10^{-4} \mathrm{M} \mathrm{Ca}^{2+}$, cytoplasmic granules aggregated in the central region of the cell, moving away from the hyaline zone between the aggregate and PM (Fig. $1 \mathrm{c}$ and e), while in the cell model prepared in the absence of $\mathrm{Ca}^{2+}$ (test solution of EGTA), the granules remained spread throughout the model (Fig. 1a and g). In the model prepared 

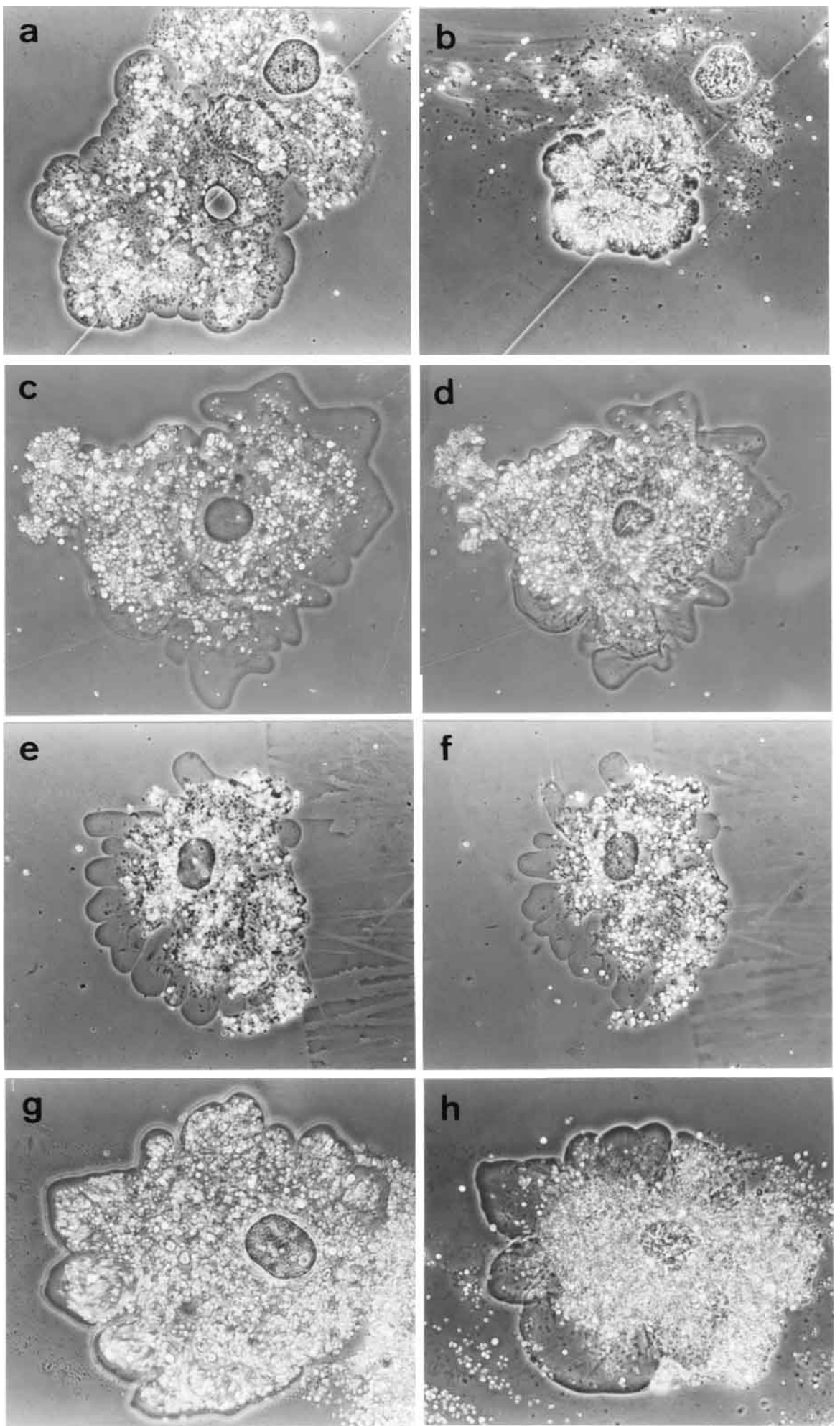

Fig. 1. Contraction of cell models induced by ATP. Phase contrast micrographs of models before (a, c, e and $g$ ) and after (b, d, f and h) addition of $1 \mathrm{mM}$ ATP. Preparation of cell models and induction of contraction were carried out using test solution of EGTA $(\mathrm{a}, \mathrm{b})$, test solution of $10^{-6} \mathrm{M} \mathrm{Ca}^{2+}(\mathrm{c}$, d), or test solution of $10^{-4} \mathrm{M} \mathrm{Ca}^{2+}(\mathrm{e}, \mathrm{f})$. A cell model was prepared in the test solution of EGTA $(\mathrm{g})$, and contraction was induced with the test solution of $10^{-4} \mathrm{M} \mathrm{Ca}^{2+}$ (h). Bar, $50 \mu \mathrm{m}$. 
in test solution of $10^{-6} \mathrm{M} \mathrm{Ca}^{2+}$, cytoplasmic granules aggregated in the central region of the cell to a lesser extent than the model prepared in test solution of $10^{-4} \mathrm{M} \mathrm{Ca}^{2+}$. These phenomena were observed in more than $85 \%$ of cell models.

We next examined the contractility of the models. Contraction was induced by introducing the test solution supplemented with $1 \mathrm{mM}$ ATP. The $\mathrm{Ca}^{2+}$ concentration of the test solution was the same as that of the test solution used to prepare the models. When the test solution of EGTA supplemented with $1 \mathrm{mM}$ ATP was introduced, the models showed marked contraction (Fig. 1b). PM also showed contraction together with the granuloplasm (Fig. 1b). In the models prepared in the presence of $10^{-6}$ or $10^{-4} \mathrm{M} \mathrm{Ca}^{2+}$, contraction of both the cytoplasm and PM was also induced, but to a lesser extent (Figs. 1d and f). When a model prepared in the test solution with EGTA was treated with a test solution of $10^{-4} \mathrm{M} \mathrm{Ca}^{2+}$ supplemented with $1 \mathrm{mM} \mathrm{ATP}$, the granuloplasm showed contraction, moving away from PM (Figs. $1 \mathrm{~g}$ and $\mathrm{h}$ ). When a model prepared in the presence of $10^{-4} \mathrm{M}$ $\mathrm{Ca}^{2+}$ was treated with a test solution of EGTA or $10^{-6} \mathrm{M}$ $\mathrm{Ca}^{2+}$, no contraction was induced and $\mathrm{PM}$ and the hyaline zone remained (data not shown). These $\mathrm{Ca}^{2+}$-dependant contraction patterns were induced in more than $80 \%$ of the cell models in each condition. Contraction of the cell models in all cases was completely inhibited by cytochalasin B (data not shown).

To examine the organization of AFs, models were stained with RP. In the models prepared in the test solution of EGTA, AFs were observed throughout the cytoplasm (Figs. 2a and $\mathrm{b}$ ), while in the models prepared in the presence of $10^{-4}$ $\mathrm{M} \mathrm{Ca}^{2+}$, most AFs were concentrated in the central region of the cell, especially around the aggregate of cytoplasmic granules (Figs. 2c and d). Some actin bundles were observed in the hyaline zone between the aggregate of the cytoplasmic granules and PM. Similar distribution of AFs was obtained in models prepared in the test solution of $10^{-6} \mathrm{M}$ $\mathrm{Ca}^{2+}$. In the models prepared in the test solution of EGTA supplemented with $1 \mathrm{mM}$ ATP, some regions of strong fluorescence in the cell model were observed, which was different from the ones before the addition of $1 \mathrm{mM}$ ATP (Figs. $3 \mathrm{a}$ and $\mathrm{b}$ ). By contrast, in the models prepared in the test solution of $10^{-4} \mathrm{M} \mathrm{Ca}^{2+}$ supplemented with $1 \mathrm{mM} \mathrm{ATP,} \mathrm{they}$ were almost same as the models before the addition of 1
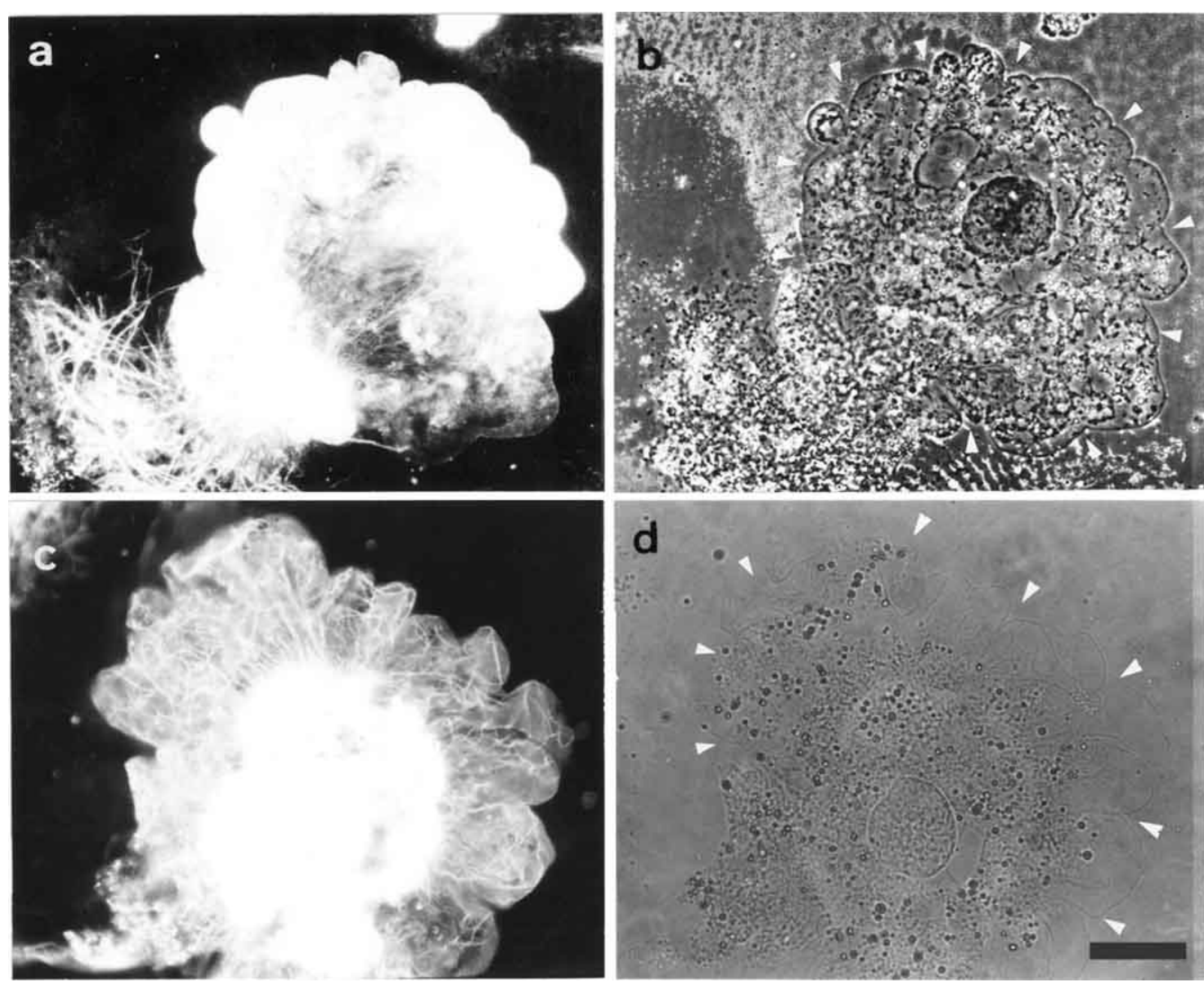

Fig. 2. Fluorescence micrographs of AFs in cell models before an addition of ATP. Fluorescence (a and c) and phase contrast (b and d) micrographs of cell models. a and b, the model prepared in test solution of EGTA; c and d, the model prepared in test solution of $10^{-4} \mathrm{M} \mathrm{Ca}^{2+}$. White triangles show the edge of the model. Bar, $30 \mu \mathrm{m}$. 

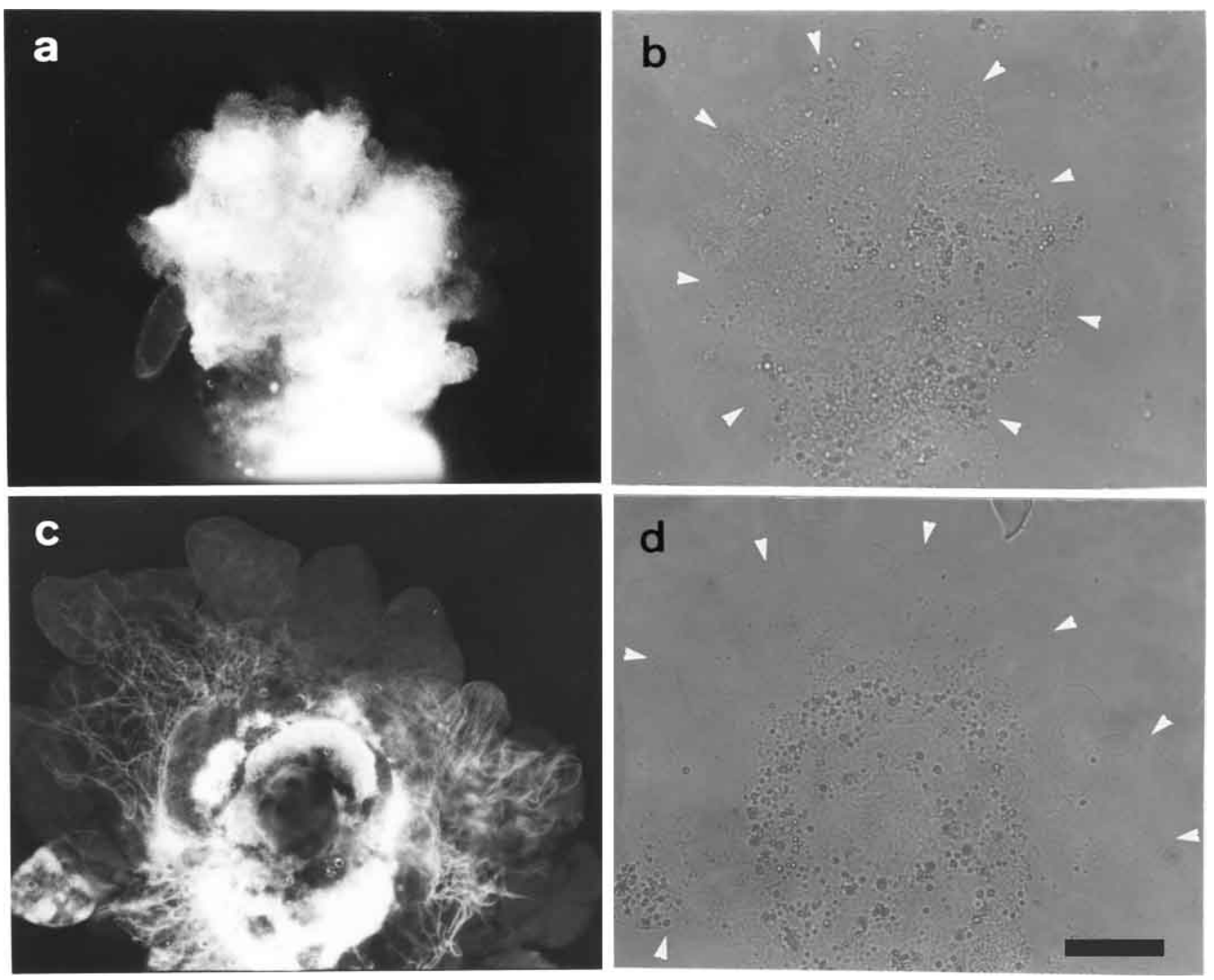

Fig. 3. Fluorescence micrographs of AFs in cell models after an addition of ATP. Fluorescence (a and c) and phase contrast (b and d) micrographs of cell models. $\mathrm{a}$ and $\mathrm{b}$, the model prepared in test solution of EGTA and treated with test solution of EGTA supplemented with 1 mM ATP; $\mathrm{c}$ and d, the model prepared in test solution of $10^{-4} \mathrm{M} \mathrm{Ca}^{2+}$ and treated with test solution of $10^{-4} \mathrm{M} \mathrm{Ca}^{2+}$ supplemented with $1 \mathrm{mM}$ ATP. White triangles show the edge of the model. Bar, $30 \mu \mathrm{m}$

mM ATP (Figs. 3c and d). These observations suggested that $\mathrm{Ca}^{2+}$ induced the detachment of AFs from PM. This possibility was further examined using the isolated PM.

\section{Isolated plasma membrane}

Amoebae were homogenized in the presence or absence of $\mathrm{Ca}^{2+}$ and centrifuged in Percoll solution (50\% Percoll, $10 \%$ sucrose, $25 \mathrm{mM}$ PIPES, $\mathrm{pH}$ 7.0). During centrifugation, fragments of PM floated to the surface form the uppermost layer. Figure 4 shows fluorescence micrographs of the isolated PM double-stained with FITC-Con A (a and c) and RP (b and d). In PM $\left(-\mathrm{Ca}^{2+}\right)$, most of the membrane fragments were stained with RP (Figs. $4 \mathrm{a}$ and b). In contrast, in PM $\left(+\mathrm{Ca}^{2+}\right)$, fewer membrane fragments were stained with $\mathrm{RP}$, and staining of filaments free of the membrane was observed (Fig. 4d, arrowheads).

Association of AFs with the isolated PM was also examined by electron microscopy. The membrane fragments were treated with myosin S-1 purified from rabbit skeletal muscle prior to fixation. As shown in Figure 5a, many AFs with S-1 fragments were associated with the PM $\left(-\mathrm{Ca}^{2+}\right)$, while no AFs were observed in PM $\left(+\mathrm{Ca}^{2+}\right)$ (Fig. 5b). Curling of PM was often observed in PM $\left(+\mathrm{Ca}^{2+}\right)$.

\section{Discussion}

Ever since the Hoffmann-Berling study (Hoffman-Berling, 1954), various cell model systems have been employed as powerful tools for analysis of various forms of cell motility. Although detergents or glycerol have generally been used to permeabilize cells, the cell models thus prepared were less suitable for studying the interaction between AFs and PM, because of the detrimental effect these reagents have on PM. In the present study, we developed a new cell model, a burst-cell model, that is expected to retain the machinery for interaction between AFs and PM.

When a cell was made to burst in the presence of $\mathrm{Ca}^{2+}$, cytoplasmic granules formed an aggregate at the central part of the cell, having left PM to form a hyaline zone (Figs. 1c and e). Staining with RP revealed accumulation of a large amount of AFs around the granuloplasm aggregate, and only a small amount of AFs was observed in the hyaline 

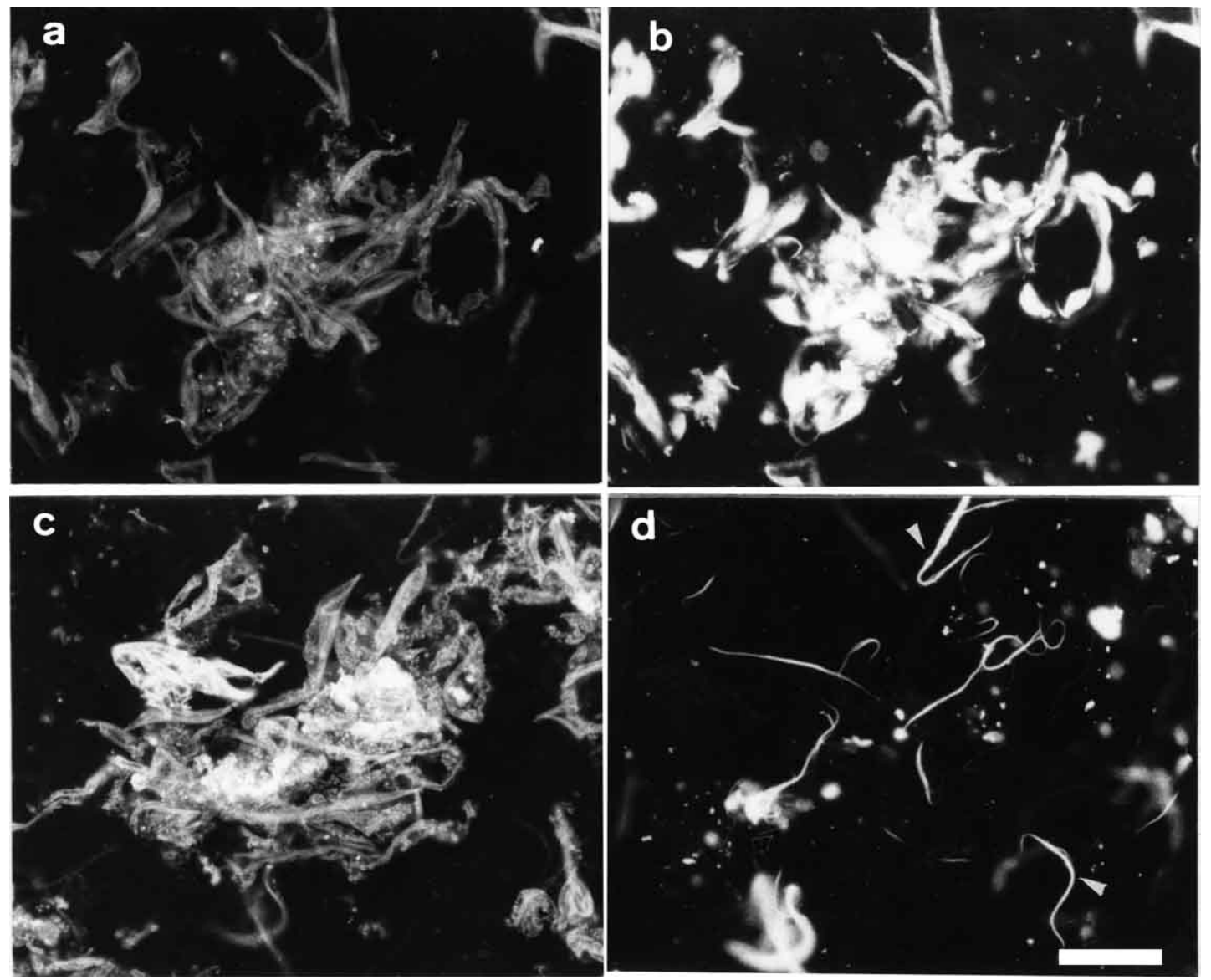

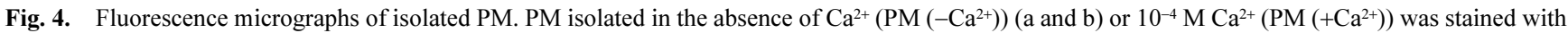
FITC-Con A (a and c) and rhodamine-phalloidin (b and d). Bar, $30 \mu \mathrm{m}$.

zone (Fig. 2c). These observations indicated that AFs became dissociated from PM, and then contracted to surround the granuloplasm aggregate, when the cell was burst in the presence of $\mathrm{Ca}^{2+}$. $\mathrm{Ca}^{2+}$ seems to have induced both dissociation of AFs from PM and contraction.

Figure 6 shows a schematic diagram of reaction patterns of Amoeba proteus observed in the present study. A large granuloplasm aggregate was formed upon bursting the cell in the presence of $\mathrm{Ca}^{2+}$ (Fig. 6b). The contraction in the presence of $\mathrm{Ca}^{2+}$ seemed to be induced with the influx of high concentration of endogenous ATP and exogenous of $\mathrm{Ca}^{2+}$ into the model. Therefore, in Amoeba proteus, $\mathrm{Ca}^{2+}$ is likely to activate actomyosin interaction as muscle cells. In addition, $\mathrm{Ca}^{2+}$ was thought to induce dissociation of AFs from PM as confirmed in the isolated PM (Fig. 5). As a result, a hyaline zone was formed between the cytoplasmic aggregate and PM. Because significant contraction had occurred in the bursting model (Fig. 6b), no further contraction was induced (Fig. 6d). On the other hand, the model prepared in the absence of $\mathrm{Ca}^{2+}$ (Fig. 6c) showed $\mathrm{Ca}^{2+}$-dependent contraction upon addition of ATP. In the presence of $10^{-4}$ or $10^{-6} \mathrm{M} \mathrm{Ca}^{2+}$, the cytoplasm contracted to form a large aggregate (Fig. 6e). This reaction is thought to be comparable to that in Fig. 6c. In the absence of $\mathrm{Ca}^{2+}$, the model contracted as a whole and no hyaline zone was formed (Fig. 6f). Although this presents a discrepancy in the mode of $\mathrm{Ca}^{2+}$ function in actomyosin contraction, we think that the concentration of the endogenous ATP might have been too low to induce contraction in the absence of $\mathrm{Ca}^{2+}$ during bursting. This view would find to be supported our report in a glycerinated model that its contraction patterns were controlled by both $\mathrm{Ca}^{2+}$ and ATP concentrations (Sonobe and Kuroda, 1986).

Dissociation of AFs from PM has been reported in the glycerinated model of Amoeba proteus (Kuroda and Sonobe, 1981). When the models were incubated in medium containing ATP and $\mathrm{Ca}^{2+}$ at very low concentration $\left(10^{-8} \mathrm{M}\right)$, an initial contraction was induced around the nucleus and then the whole granuloplasm contracted. The contracted granuloplasm was surrounded by a layer of AFs, suggesting that AFs had become dissociated from PM. In the present model, PM contracted together with granuloplasm in the absence of $\mathrm{Ca}^{2+}$ (Fig. 1b). The association between AFs and PM may have been weakened by 

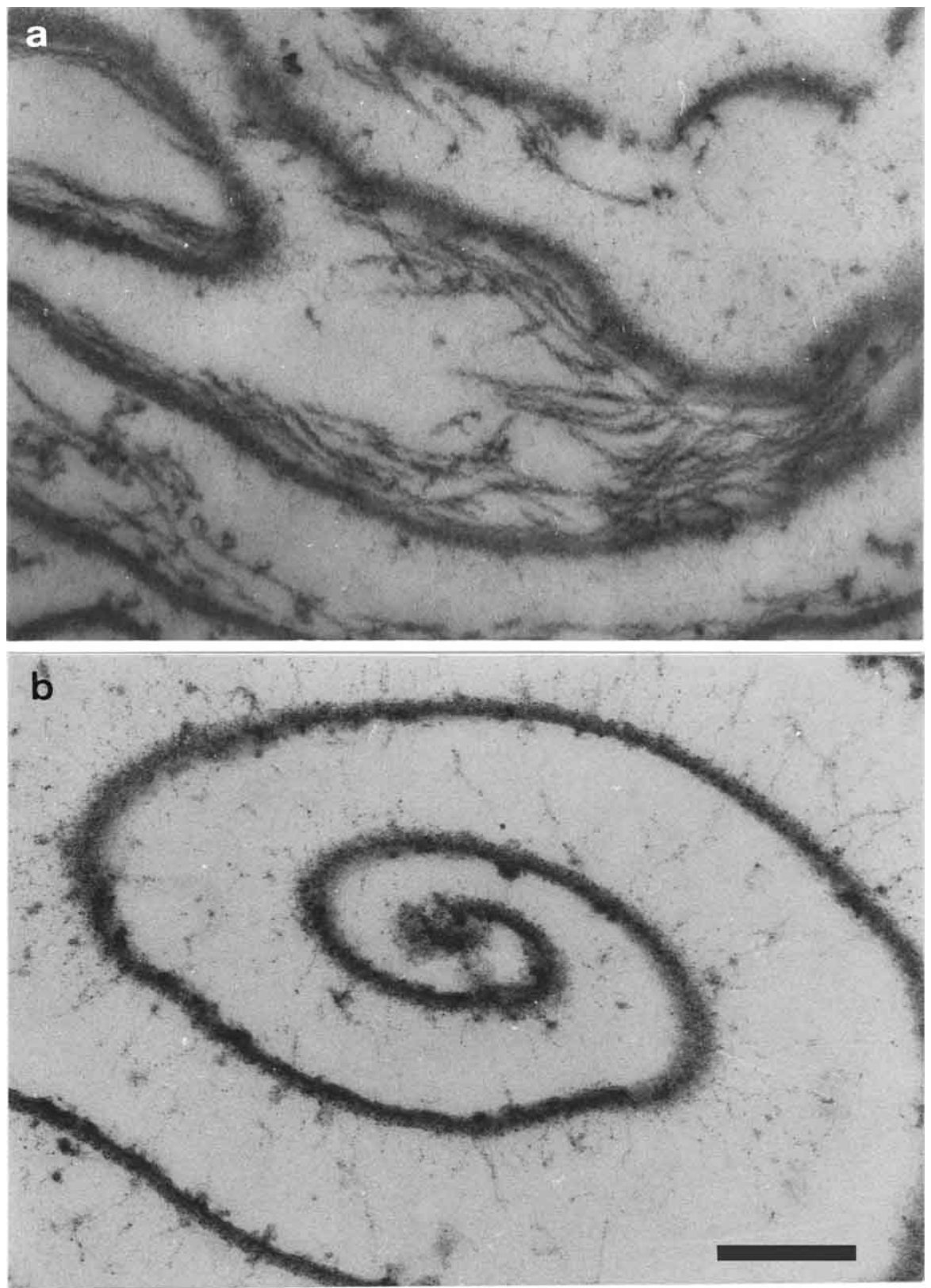

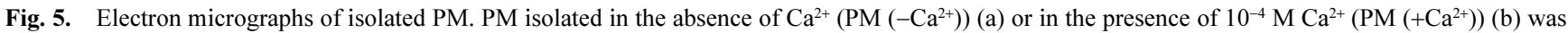
incubated with rabbit skeletal muscle myosin S-1 prior to fixation for electron microscopy. Bar, $0.1 \mu \mathrm{m}$.

glycerin treatment, resulting in dissociation of AFs from $\mathrm{PM}$ at a very low $\mathrm{Ca}^{2+}$ concentration. Another possibility is that some $\mathrm{Ca}^{2+}$-sensitizing factor regulating the interaction between AFs and PM had been lost during glycerin treatment.

AFs were associated with PM $\left(-\mathrm{Ca}^{2+}\right)$ but not with PM $\left(+\mathrm{Ca}^{2+}\right)$. This was confirmed by both RP staining (Fig. 4) and electron microscopy (Fig. 5). Dissociation of AFs might occur during homogenization of amoeba in the presence of $\mathrm{Ca}^{2+}$. In non-muscle cells, various actin depolymerization and/or fragmentation proteins have been reported (Fukui, 1993). It is unlikely, however, that the disappearance of AFs from PM was induced by a $\mathrm{Ca}^{2+}$-dependent actin depolymerizing or severing factor(s), because AFs free of PM were observed in the fraction of PM $\left(+\mathrm{Ca}^{2+}\right)$ (Fig. $\left.4 \mathrm{~d}\right)$. AFs also remained after the cells had burst in the solution of high $\mathrm{Ca}^{2+}$ concentration (Fig. 2c).

Taylor et al. (1980) reported higher concentrations of free $\mathrm{Ca}^{2+}$ at the tail region and pseudopod tip in Amoeba proteus. Considering this together with the results obtained in the 


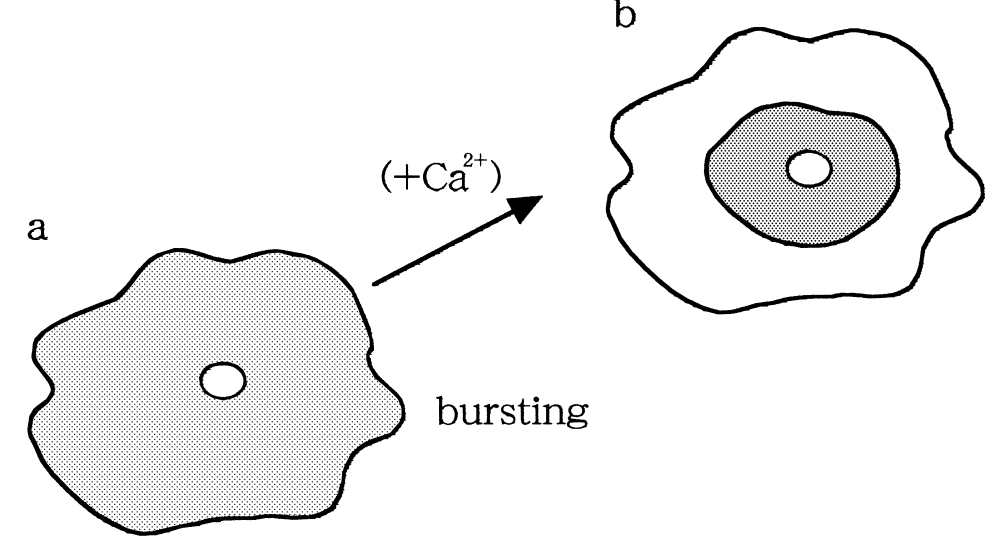

$\mathrm{b}$

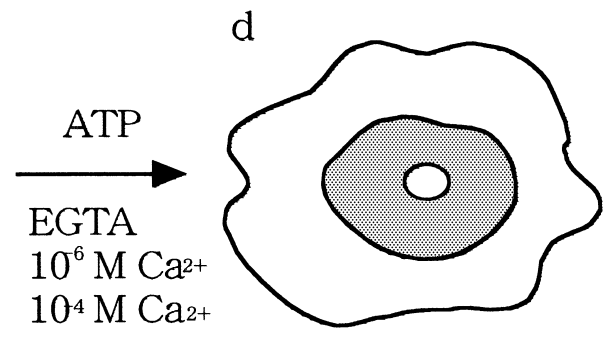

d

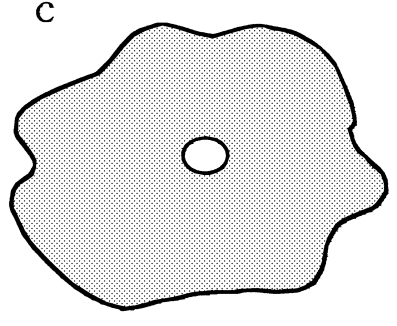

e
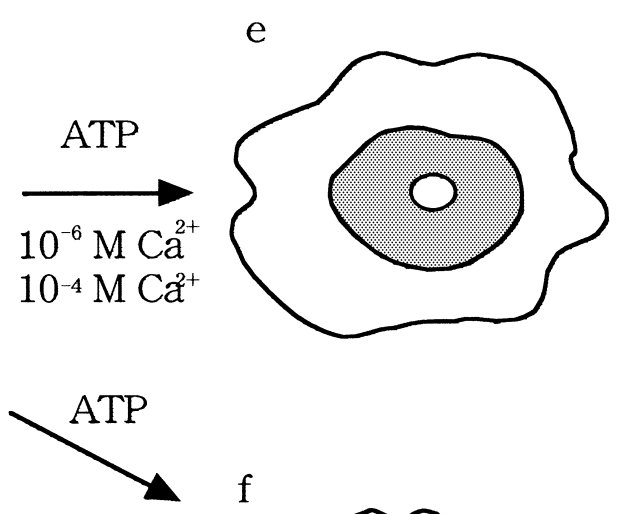

EGTA f

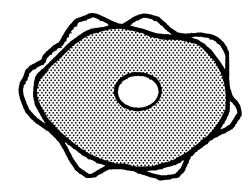

Fig. 6. Schematic diagram of reaction patterns of living and burst Amoeba. Amoeba proteus (a) was burst in the presence (b) or absence (c) of Ca ${ }^{2+}$ to produce a cell model. The former model (b) showed no contraction upon addition of ATP with any concentration of Ca ${ }^{2+}(\mathrm{d})$, while the latter (c) showed Ca ${ }^{2+}$ dependent contraction; (e), ATP with $10^{-4}$ or $10^{-6} \mathrm{M} \mathrm{Ca}^{2+}$; (f), ATP with EGTA. For details, see text.

present study, it is likely that $\mathrm{Ca}^{2+}$ induces contraction at the tail region to increase hydrostatic pressure in the cell, and at the same time, induces dissociation of AFs from PM at the pseudopod tip, resulting in extension of the pseudopod. To explore this possibility, the dynamics of free $\mathrm{Ca}^{2+}$ must be reexamined and the molecular mechanism of $\mathrm{Ca}^{2+}$ regulation in the interaction between AFs and PM must be elucidated.

\section{References}

Allen, R.D. 1961. A new theory of amoeboid movement and protoplasmic streaming. Exp. Cell Res. Suppl., 8: 17-31.

Cande, W.Z. 1980. A permeabilized cell model for studying cytokinesis using mammalian tissue culture cells. J. Cell Biol., 87: 326-335.

Cobbold, P.H. 1980. Cytoplasmic free calcium and amoeboid movement. Nature, 285: 441-446.

Condeelis, J.S. 1977. The isolation of microquantities of myosin from Amoeba proteus and Chaos carolinensis. Anal. Biochem., 78: 374-394.
Condeelis, J.S. 1977. The self-assembly of synthetic filaments of myosin isolated from Chaos carolinensis and Amoeba proteus. J. Cell Sci., 25: $387-402$.

Cramer, L. and Mitchison, T.J. 1993. Moving and stationary actin filaments are involved in spreading of postmitotic PtK2 Cells. J. Cell Biol., 122: 833-843.

Fukui, Y. 1993. Toward a new concept of cell motility: cytoskeletal dynamics in amoeboid movement and cell division. Int. Rev. Cytol., 144: $85-127$.

Grebecki, A. 1990. Dynamics of the contractile system in the pseudopodial tips of normally locomoting amoebae, demonstrated in vivo by videoenhancement. Protoplasma, 154: 98-111.

Grebecki, A. 1994. Membrane and cytoskeleton flow in motile cell with emphasis on the contribution of free-living amoebae. Int. Rev. Cytol., 148: $37-48$.

D'Haese, J. and Hinssen H. 1974. Structure of synthetic and native myosin filaments from Amoeba proteus. Cell Tiss. Res., 151: 323-335.

Hoffmann-Berling, H. 1954. Adenosintriphosphat als Betriebsstoff von Zellbewegungen. Biochim. Biophys. Acta, 14: 182-194.

Kuroda, K. and Sonobe, S. 1981. Reactivation of a glycerinated model of amoeba. Protoplasma, 109: 127-142. 
Lee, W.J., Kolega, J., and Taylor D.L. 1991. Modulation of contraction by gelation/solation in a reconstituted motile model. J. Cell Biol., 144: 1005-1015.

Lee, W.J. and Taylor, D.L. 1993. In vitro models of tail contraction and cytoplasmic streaming in amoeboid cells. J. Cell Biol., 123: 345-356.

Margossian, S.S. and Lowey, S. 1982. Preparation of myosin and its subfragments from rabbit skeletal muscle. Method Enzymol., 85: 55-71.

Miyata, H., Nisiyama, S., Akashi, K., and Kinosita, K. 1999. Protrusive growth from giant liposomes driven by actin polymerization. Proc. Natl. Acad. Sci. USA, 96: 2048-2053.

Prescott, D.W. and James, T.W. 1955. Culturing of Amoeba proteus on Tetrahymena. Exp. Cell Res., 8: 256-258.

Sonobe, S. and Kuroda, K. 1986. Ultrastructural aspects of a glycerinated model of Amoeba proteus. Protoplasma, 130: 41-50.

Stockem, W., Hoffmann, H.U., and Gawlitta, W. 1982. Spatial organization and fine structure of the cortical filament layer in nomal locomoting Amoeba proteus. Cell Tiss. Res., 221: 505-519.

Taylor, D.L., Condeelis, J.S., Moore, P.L., and Allen, R.D. 1973. The contractile basis of amoeboid movement. III. The chemical control of motility in isolated cytoplasm. J. Cell Biol., 59: 378-394.

Taylor, D.L., Rhodes, J.A., and Hammond, S.A. 1976. The contractile basis of amoeboid movement.áU. Structure and contractility of motile extracts and plasmalemma-ectoplasm ghosts. J. Cell Biol., 70: 123-143. Taylor, D.L., Condeelis, J.S. and Rhodes, J.A. 1977. The contractile basis of amoeboid movement III. Structure and dynamics of motile extracts and membrane fragments from Dictyostelium discoideum and Amoeba proteus. Prog. Clin. Biol. Res., 17: 581-603.

Taylor, D.L., Wang, Y.L., and Heiple, J.M. 1980. The contractile basis of amoeboid movement.áZ. The distribution of fluorescently labeled actin in living amebas. J. Cell Biol., 86: 590-598.

Taylor, D.L., Blink, J. R., and Reymond, G. 1980. The contractile basis of amoeboid movement. III Aequorin luminescence during amoeboid movement, endocytosis, and capping. J. Cell Biol., 86: 599-607.

Theriot, J.A. and Mitchison, T.J. 1991. Actin microfilament dynamics in locomoting cells. Nature, 352: 126-131.

Yanai, M., Kenyon, C.M., Butler, J.P., Macklem, P.T., and Kelly, S.M. 1996. Intracellular pressure is a motive force for cell motion in Amoeba proteus. Cell Motil. Cytoskel., 33: 22-29.

Yumura, S. and Fukui, Y. 1998. Spatiotemporal dynamics of actin concentration during cytokinesis and locomotion in Dictyostelium. J Cell Sci., 111: 2097-2108.

(Received for publication, July 21, 2000

and in revised form, October 4, 2000) 